\title{
PENSATA
}

\section{REFLEXÕES SOBRE EMPRESAS MULTINACIONAIS E A PANDEMIA DE COVID-19}

\author{
€Mohamed Amal, Markus Blumenschein ${ }^{\Omega}$, ${ }^{\ddagger}{ }^{1}$ Sílvio Luís de Vasconcellos \\ EUniversidade Regional de Blumenau-FURB, Blumenau, SC (Brasil) \\ $\Omega$ T-Systens - Blumenau, SC (Brasil) \\ ${ }^{\sharp}$ Escola Superior de Propaganda e Marketing - ESPM, São Paulo, (Brasil)
}

\section{INTRODUÇÃO}

O ano 2020 será rotulado na história como o Ano da Pandemia de COVID-19. Pela primeira vez, nos cem anos de maior avanço tecnológico e de qualidade de vida que a humanidade já vivenciou, uma crise sanitária parou a economia e se candidata a ser o grande reset de consumo, produção e investimentos (McKinsey \& Company, 2020). As primeiras impressões indicam que se trata de um fenômeno potencializador de tendências na relação entre tecnologia e comportamento do consumidor e entre políticas econômicas e sociedade. Se por um lado a tecnologia abrandou alguns efeitos da pandemia, por outro lado o papel do Estado na economia ganhou outra dimensão, podendo também refletirse em maior proteção aos ativos produtivos com reflexos nas grandes cadeias globais de valor. Se, por um lado já era evidente a intensificação de políticas protecionistas (Stiglitz, 2018), por outro verifica-se uma resposta das multinacionais pela regionalização das cadeias de valor (Enderwick \& Buckley, 2020).

Antes de tratar sobre os temas delimitados, cabe discutir os motivos para tratar de empresas multinacionais na Pandemia. O primeiro motivo, trata da importância de entender que as empresas multinacionais são resultado e agentes proativos da globalização, como são conhecidas, pelo menos, desde a era pós-segunda guerra mundial, particularmente, após os acordos de Bretton

\footnotetext{
${ }^{1}$ Contato do autor - E-mail: silvio.vasconcellos@espm.br
}

Woods que estabeleceram o sistema e a configuração da governança da economia global.

O segundo motivo leva em conta que, para os países em desenvolvimento, as empresas multinacionais, depois de um longo período, entre os anos 1960, 1970 e 1980, quando foram criticadas intensivamente, passaram a ser vistas dentro desse novo cenário da globalização, nos anos 1990, como vetores de desenvolvimento econômico. As multinacionais promoveram o catching-up tecnológico (Abramovitz, 1986; Mu \& Lee, 2005; Parente et al., 2020), social e econômico para muitos países em desenvolvimento e, portanto, se transformaram não apenas em um vetor de dinamismo global, mas também um componente estratégico dentro das políticas de desenvolvimento econômico de vários países.

O terceiro motivo, é que, desde o início dos anos 2000, as empresas multinacionais de países emergentes começaram a se transformar em desafiantes e competidores, no contexto global, ganhando força e dinâmica em função da própria globalização.

Em suma, são vários fatores que fazem com que o tema seja interessante, importante e deverá contribuir para o entendimento das mudanças em curso e que, com a Pandemia de COVID-19, ganharam maior relevância. Há a compreensão que será um processo longo que demandará das organizações e instituições ajustar, mudar, remodelar e reconfigurar o seu papel na economia global. 
O objetivo central deste ensaio é provocar reflexões sobre os efeitos da pandemia de COVID19 nas empresas multinacionais. Mais especificamente, são oferecidos elementos para a discussão de como multinacionais situadas em países emergentes estão modificando suas estratégias. Para ilustrar essas reflexões, neste ensaio combina-se a percepção de acadêmicos ligados a negócios internacionais e de um gestor de uma multinacional alemã com operações no Brasil, de onde atende a diferentes segmentos econômicos espalhados pelo mundo. Como resultado, são sugeridos temas de pesquisas para a era pós-pandemia.

\section{Efeitos da Pandemia sobre a Globalização e as Empresas Multinacionais.}

Nesta seção, é oferecida uma reflexão sobre as implicações da Pandemia de COVID-19 sobre Negócios Internacionais e, especificamente, sobre globalização e empresas multinacionais. A seção está estruturada em quatro tópicos: efeitos e implicações macroeconômicos da Pandemia, efeitos específicos sobre as multinacionais, efeitos sobre a globalização e os efeitos no investimento direto em países emergentes.

\subsection{Efeitos e implicações macroeconômicos da Pandemia}

O ambiente macroeconômico pode assumir um papel determinante nas decisões que as multinacionais venham a tomar em decorrência da pandemia. É crucial que se entenda a dinâmica dessas empresas, particularmente, dos fluxos de investimentos e da distribuição do capital global. Embora não se saiba com clareza os impactos da
Pandemia sobre negócios internacionais, é possível explorar as várias mudanças já em curso no cenário das empresas multinacionais, desde 2017, especialmente com relação ao avanço das forças deglobalizantes da economia.

Esse processo de transformação macroeconômica não é diretamente decorrente da Pandemia em si. A Pandemia de COVID-19 se apresenta como um momentum e um evento de ruptura econômica que tende a acelerar as mudanças já em curso, tanto em termos tecnológicos, como em relação às estratégias de empresas multinacionais.

Do ponto de vista das próprias implicações da Pandemia de COVID-19, existem diversos motivos para sistematizar uma reflexão a seu respeito. Trata-se de um evento histórico relativamente raro e, quando ocorre, pode gerar mudanças significativas como choque externo, tanto em termos da oferta como da demanda. A última pandemia que a humanidade enfrentou com severidade, atingindo a economia global, foi a Gripe Espanhola em 1917, no final da 1a Guerra Mundial, que durou até dezembro de 1919. Aquela pandemia teve, particularmente, um efeito devastador, implicando em perdas humanas de quase 50 milhões de pessoas. A Gripe Espanhola gerou uma série de efeitos, não apenas econômicos, mas especialmente sociais e de ordem política. Antes da Pandemia de 1917, tivemos outras pandemias em 1812, antes ainda a Peste Negra, na Idade Média, e assim por diante. Portanto, não é um fenômeno corrente, muito menos trivial. Entretanto, entende-se que a pandemia acontece, justamente, num momento ou numa época em que a humanidade dispõe de muito mais domínio sobre a tecnologia e sobre o controle dessas catástrofes sanitárias. 
2.5

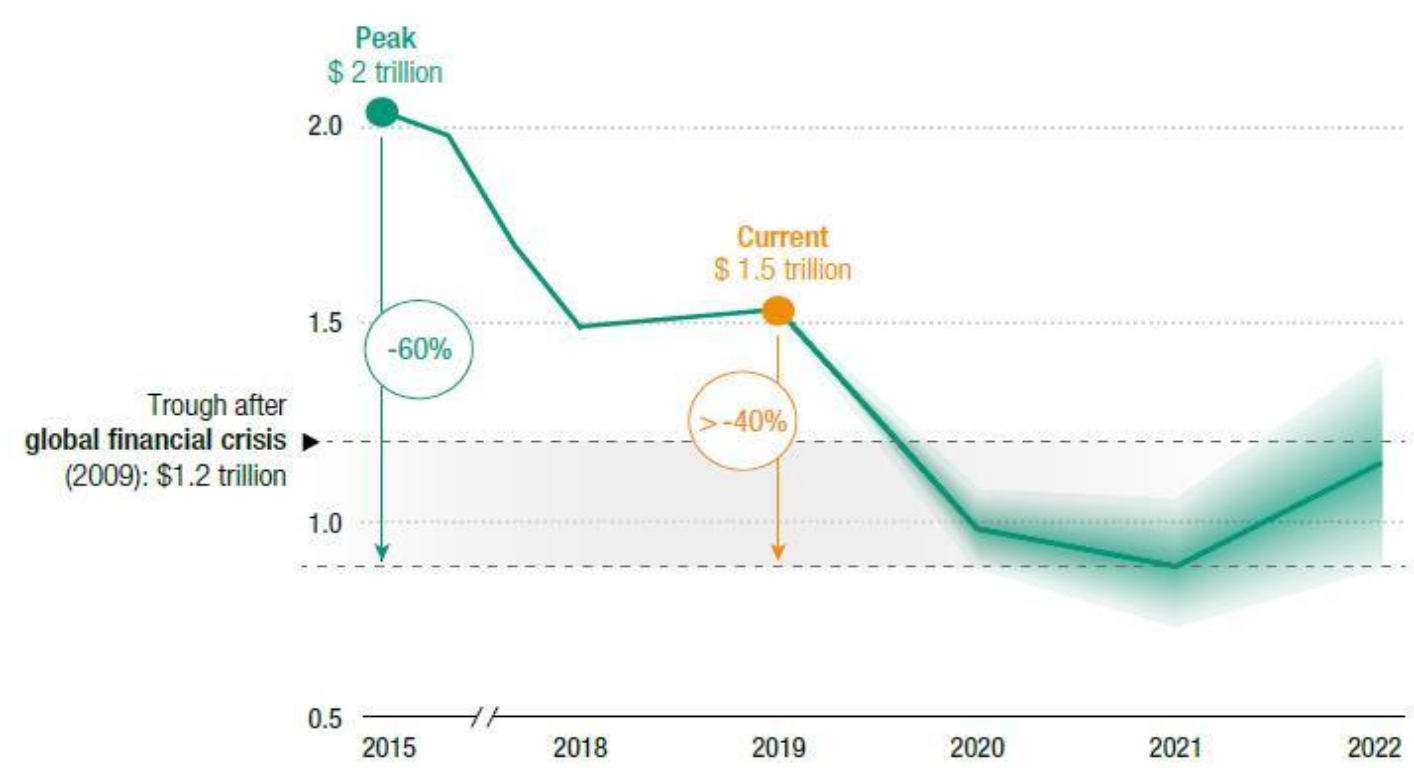

Figura 1. Projeção de Fluxo de Investimento Direto Externo no mundo pós-COVID-19. Fonte: World Investment Report (2020: p.2)

A Pandemia de COVID-19 é diferente das manifestações das crises anteriores. Seu impacto epidemias anteriores. Ainda em 2020, não é imediato é um choque da oferta, que gera um possível quantificar e prever todos os seus impactos, no entanto as projeções de fluxos de Investimento Direto Externo (FDI) não são nada otimistas, conforme Figura 1. É uma crise sanitária que tem consequências diretas na economia e nas choque da demanda em nível global, representado por desemprego e diminuição da renda. Ela representa, na sua amplitude estrutural, uma verdadeira ameaça à globalização, como demonstrado na Figura 2. finanças, de tal modo que ela reúne todas as

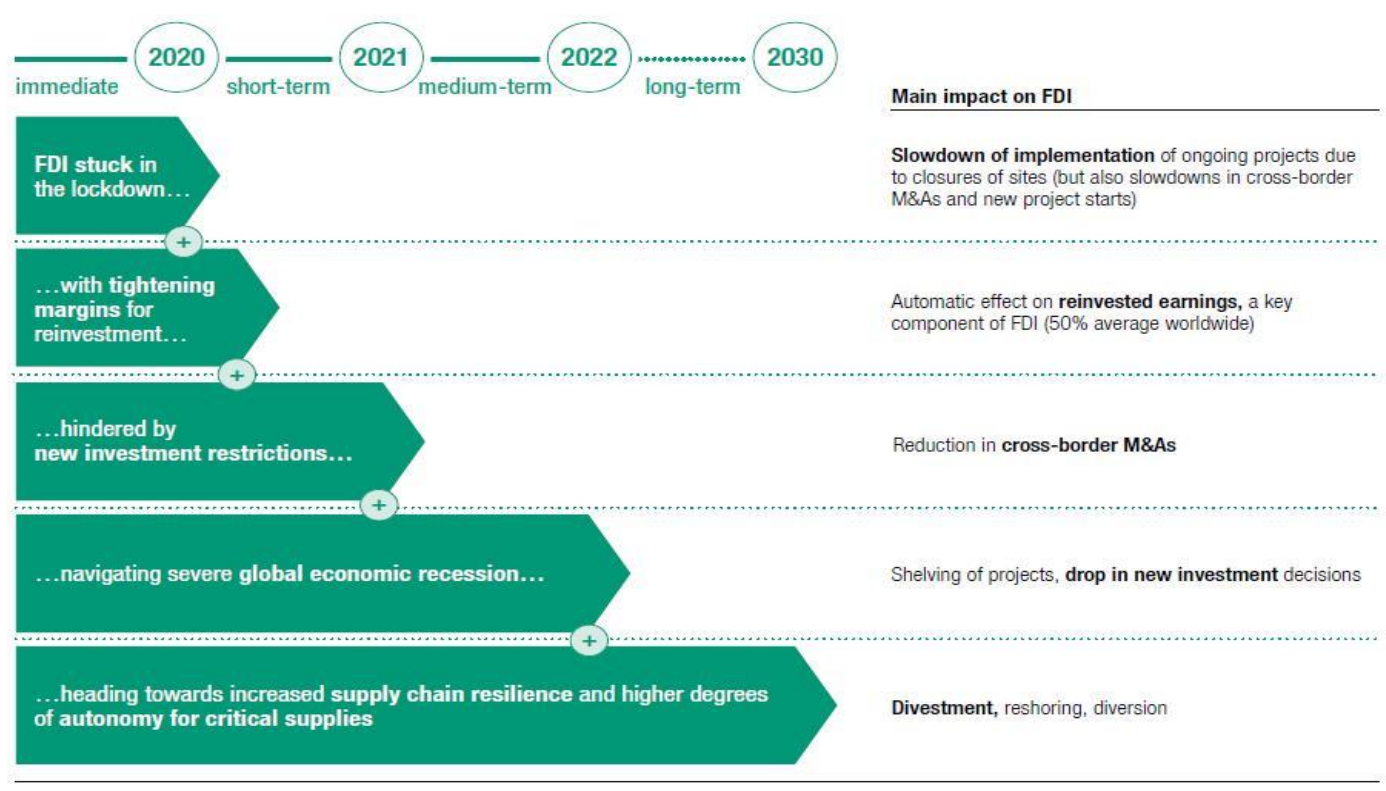

Figura 2. Impacto da Pandemia no Fluxo de Investimento Direto Externo e nos mecanismos de transmissão Fonte: World Investment Report (2020: p.3) 
Os dados divulgados por diversas instituições multilaterais, como o Fundo Monetário Internacional (FMI, 2020), mostram uma queda do PIB mundial da ordem de 4,9\%. Embora seja uma média geral sobre o desempenho econômico, a queda esperada é ainda mais acentuada para as economias desenvolvidas, na ordem de $8 \%$, e uma redução moderada nas economias emergentes, algo em torno de 3\% do PIB, conforme ilustrado na Figura 3.

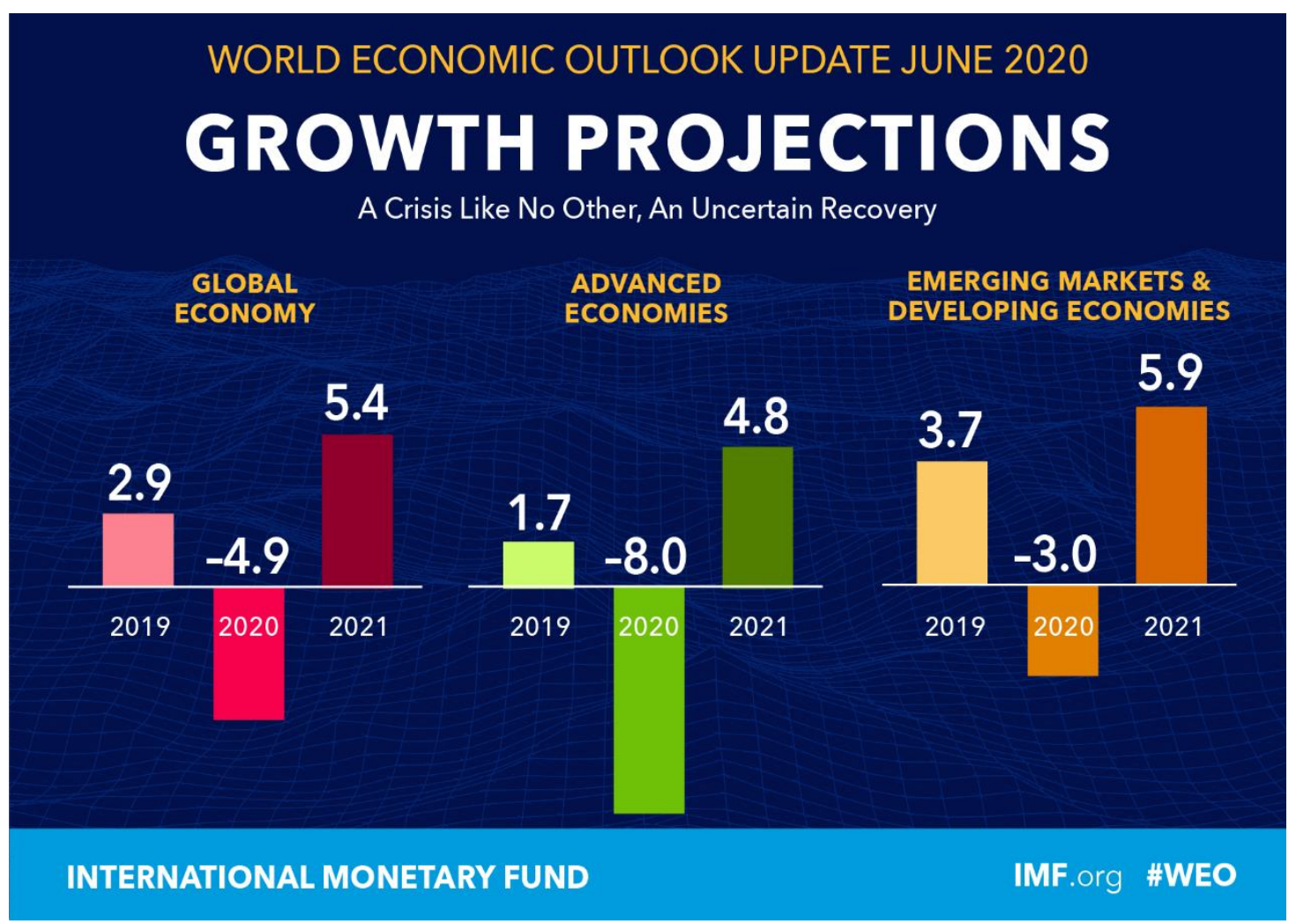

Figura 3. Projeções de Crescimento Econômico Fonte: Fundo Monetário Internacional.

Embora tais efeitos sejam generalizados entre todos os países e grupos de economias, as projeções apontam também para uma recuperação, já a partir do segundo semestre de 2020. Segundo as previsões do FMI, no ano de 2021, a economia mundial deverá crescer de aproximadamente $5,4 \%$, enquanto as economias avançadas e emergentes deverão registrar taxas de crescimento de 4,8\% e 5,9\%, respectivamente, sugerindo uma recuperação no formato de ' $V$ ' (Rodeck, 2020).

Há duas hipóteses fundamentais por trás desse cenário. Primeiro, as medidas de isolamento social prevalecerão, no máximo, até o meio do ano, e que de julho a agosto em diante, os trabalhadores retomarão suas atividades normalmente, os consumidores resgatarão o ritmo e o volume de compras pré-crise e todos os setores de atividade recuperarão rapidamente os níveis de produção prévios. Segundo, esse cenário conta com os governos sendo bem-sucedidos na implementação de medidas fiscais e monetárias para sustentar a economia, minimizando os efeitos sobre famílias, empresas e sistema financeiro, conforme proposto pelo Instituto de Pesquisa Econômica Aplicada (IPEA)(Rocha, 2020).

Efeitos econômicos desta magnitude, necessariamente, afetarão os próprios investimentos das empresas, sua lucratividade, e, portanto, o crescimento. Tais implicações poderão gerar uma reestruturação de setores, acelerando os processos de integração digital e surgimentos de novos players nos respectivos mercados, além de constituir-se num verdadeiro gatilho para o desenvolvimento de novas tecnologias e soluções 
inovadoras para a oferta e distribuição de bens e serviços na escala nacional e global.

Embora existam semelhanças com a Crise SubPrime2008, a Pandemia de COVID-19 apresenta características específicas. Seus efeitos são de ordem conjuntural, afetando, em primeira instância, os agregados econômicos de curto prazo, tais com PIB, renda e emprego. Entretanto, seus efeitos carregam um potencial significativo para estimular e acelerar mudanças estruturais, tais como mudanças tecnológicas, setoriais e a própria forma de governança da economia global.

\subsection{Efeitos e implicações para a globalização}

Diversas manifestações deste período de pandemia já estavam em curso, tal como protecionismo, dificuldades de gestão das cadeias globais de suprimento, fluxos de investimento estrangeiro direto, digitalização etc. Talvez a reflexão a ser feita é em que medida e que extensão a Pandemia de COVID-19 irá acelerar tais processos de de-globalização. O termo deglobalização, cunhado primeiramente na mídia econômica especializada (James, 2018), passou a ser entendido como um fenômeno em curso que representa uma resposta das cadeias globais de valor a movimentos protecionistas no final da segunda década do século XXI (Irwin, 2020; Petricevic \& Teece, 2019; Stiglitz, 2018).

Ainda cabe refletir em que medida tais processos e forças podem reverter a globalização como fenômeno universal e quais seus impactos particularmente sobre as Cadeias Globais de Valor e empresas multinacionais. Numa perspectiva de gestão de negócios internacionais, discutir os rumos e evolução da globalização neste contexto, necessariamente implica em avaliar as mudanças nas estratégias e desempenho das empresas multinacionais como um agente fundamental da globalização. Segundo a UNCTAD(2020), em seu relatório denominado Monitor de Tendências de Investimentos, que normalmente é publicado em outubro, mas que emite projeções no caso de situações atípicas, já havia sido detectada uma redução significativa de fluxos internacionais de investimento direto de em torno de 30 a 40\%, nos dois anos posteriores. No mesmo relatório, consta que, neste cenário, mais da metade das empresas multinacionais revisaram suas expectativas de lucro, com tendência para uma redução da lucratividade das empresas multinacionais da ordem de $50 \%$. Essa questão é particularmente importante se consideramos que mais de $50 \%$ dos novos investimentos são lucros reinvestidos.

Numa perspectiva otimista, a redução de 30 a $40 \%$ do estoque de investimento é um cenário bastante provável. Além disso, em relação a projetos greenfield (Silva \& Fleury, 2012; Werlang et al., 2014), espera-se também uma redução de investimento estrangeiro direto, por representarem níveis de comprometimento de muito mais longo prazo para as empresas. As projeções da UNCTAD apontam para uma redução de todas as modalidades de investimento direto externo, especialmente uma redução aproximada de $70 \%$ das operações médias de fusões e aquisições.

Neste cenário, de mudanças rápidas e enfraquecimento das forças globalizantes, surgem outras questões, como a reversibilidade da globalização. É possível que forças de-globalizantes podem, com a ajuda da Pandemia, minar a globalização e comprometer a expansão das empresas multinacionais. Os dados da UNCTAD indicam que, i) o estoque de entrada de investimento direto interno no mundo, em 2018, foi de $U \$ 32,3$ trilhões, sendo $1 / 3$ de multinacionais de economias emergentes; ii) os ativos de subsidiárias estrangeiras representam U\$ 75,9 trilhões; e iii) os ativos estrangeiros no total de ativos de empresas representa $60 \%$ para países desenvolvidos e $27 \%$ para multinacionais de economias emergentes.

Embora a Pandemia de COVID-19 seja devastadora de ponto de vista econômico e social, liquidar tais ativos externos é impossível por diversos motivos. Por exemplo, dificuldade de lidar com problemas de gestão da liquidação de tais ativos, dificuldade de substituí-los, falta de alternativas de como substituir a oferta de empresas multinacionais e a limitação do comércio internacional em garantir oferta global de produtos com base apenas nos mecanismos das vantagens comparativas ou absolutas. 
As respostas das multinacionais a essas indagações são de difícil previsão. Seguramente, é uma oportunidade para procurar entender e aprofundar o entendimento sobre as estratégias globais de empresas e a construção e alternância de suas vantagens de propriedade, neste contexto. As mudanças que afetam a governança global e o efeito Pandemia de COVID-19, embora impliquem em redução significativa dos fluxos de comércio internacional e de investimento estrangeiro direto, não deverão interromper as cadeias globais de valor, mas pressioná-las para sua reconfiguração.

Há indícios de que, em vez de cadeias globais de valor, vamos migrar, dentro do cenário de mudanças da Pandemia, para cadeias regionais de valor (Enderwick \& Buckley, 2020; Gereffi, 2020). É possível o surgimento de cadeias Sub-Asiáticas, cadeias do Leste Europeu, cadeias da América do Sul. Essas cadeias regionais de valor vão se sustentar dentro de vários arranjos de cooperação e integração regionais geograficamente próximas. Isso sugere uma tendência para rever as formas de servir os mercados externos, uma redistribuição dos projetos de investimento entre as regiões de modo a manter as vantagens de economias de escala, mas, sobretudo, uma reorientação dos investimentos de multinacionais no intuito de otimizar a alocação de recursos entre as regiões e favorecer mecanismos de maior comprometimento das empresas com as metas regionais.

O enfraquecimento das cadeias globais de valor terá como consequência direta o recuo dos investimentos diretos verticais, e, portanto, uma expansão maior de investimentos horizontais. Portanto, teremos uma transição para mais de um tipo de estratégia de busca de mercado (marketseeking) em vez de busca de eficiência, por exemplo (efficient-seeking) (Wadhwa \& Reddy, 2011), ou outras formas de atuações das empresas.

É possível, também, prever um recuo de estratégias de buscas de ativos estratégicos. Alianças e fusões estratégicas serão altamente controladas e regulamentadas pelo poder do Estado, justamente para poder controlar o processo de transferência de tecnologia e de controle da propriedade intelectual.
2.3 Efeitos no investimento direto em países emergentes

O papel do Estado deve sofrer revisão quanto às políticas neoliberais que vinham se consolidando nas últimas décadas. Primeiro, o Estado pode interferir em termos de remodelar e reconfigurar o conceito de setor estratégico. Setores estratégicos poderão ganhar um significado distinto da perspectiva tradicional, como de petróleo, gás, tecnologia nuclear etc. Em outros termos, qualquer atividade econômica pode se converter em setor potencialmente estratégico do ponto de vista geopolítico e, portanto, passa a se beneficiar de exceções relativos aos critérios de não discriminação da Organização Mundial do Comércio (OMC). Segundo, é importante salientar que, nesse contexto, as empresas multinacionais de origem de economias emergentes deverão enfrentar adicionalmente problemas e barreiras de natureza específica nas suas condições e capacidades de desenvolvimento de vantagens de propriedade.

A expansão internacional de empresas multinacionais de países emergentes mostra que esta trajetória percorreu diversos ciclos. Ciclo de down-market, quando a sua expansão era baseada em investimentos em outras economias emergentes (Amal, 2016; Tomelin et al., 2018), com forte motivação de busca de mercado, ou de recursos naturais. Entretanto, a sua expansão mais recente é do tipo up-market, caracterizando um ciclo de investimento sul-norte (Ramamurti \& Singh, 2009), que são estratégias orientadas para busca de ativos estratégicos, de conhecimento, de tecnologia, de inovação e, portanto, investimentos maciços em países como os EUA, Europa, especialmente empresas chinesas, mas, também, brasileiras.

Esse processo, a meu ver, deverá sofrer fortes pressões para limitar e controlar seu escopo, não só apenas por questões geopolíticas, mas também por questões relativas a mudanças graduais do papel do governo na reconfiguração das regras de competição e de controle das atividades de fusões e aquisições e de transferência de tecnologia. 
Reflexões sobre Empresas Multinacionais e a Pandemia de Covid-19

\section{Efeitos imediatos da Pandemia nas Empresas Multinacionais.}

Na perspectiva da gestão de multinacionais, é necessário analisar alguns efeitos imediatos que as mudanças nas cadeias de valor podem e estão provocando. Há efeitos em certos serviços básicos, como a alimentação e energia, mais especificamente $\mathrm{o}$ petróleo. Tais cadeias continuam fortemente globalizadas, independentemente da intervenção do Estado.

Além das diferenças entre os países, há mudanças específicas em sub-regiões nacionais que precisam ser levadas em conta, dado que o contexto regional pode oferecer diferentes vantagens e desvantagens para as multinacionais operarem (da Cruz et al., 2020). Há sinais de há uma reorganização em curso quanto ao papel do Estado. Há discussões na Europa e nos Estados Unidos sobre a dependência da China (Rapoza, 2020). Embora seja uma tendência no discurso corrente, há dependências da China difíceis de serem superadas. Na área de minerais de terras raras, por exemplo, o Brasil depende da importação desses minérios, embora os tenha em grande quantidade (Liy, 2019). O que falta é a capacidade de processá-los e, principalmente, o conhecimento dessas capacidades tecnológicas específicas. Possivelmente, o Estado vai influenciar o investimento em ciência e inovação, se estendendo para várias áreas, inclusive na área econômica e na saúde, desde que não predomine uma tendência de falta de embasamento científico nas ações estratégicas governamentais.

Mais especificamente sobre a reorganização de cadeias de valor, muito depende também para onde os investimentos e o capital vão, pois são muito fluidos. Para as multinacionais é imperativo haver segurança política, não só no Brasil. Também em outros países em desenvolvimento há dificuldades de enxergar isso como uma ameaça ou oportunidade. Isso gera insegurança para os investidores. Algumas evidências desse novo padrão de resposta de multinacionais podem ser observados na T-SYSTEMS, subsidiária brasileira da gigante alemã TELEKOM, que a partir do Brasil, atende clientes em vários países, de diferentes setores, como o automotivo, a manufatura, as telecomunicações e a agroindústria, dando suporte de software e serviços de infraestrutura de TI, assim como outras multinacionais operam no Brasil. A T-SYSTEMS tem clientes que já eram atendidos via digital. Porém, nos últimos anos, outros clientes mudaram ou estão mudando para um modelo mais digital, estabelecendo canais digitais de comunicação com a T-SYSTEMS e com os seus clientes. Durante a Pandemia de COVID-19, aquilo que foi planejado, nos últimos anos, com alguma resistência ganhou aceleração e desencadeou-se um processo de digitalização extremamente rápido. Os clientes que demoraram mais a implantar a digitalização, na transição, passaram a sentir dificuldades, visto que a venda física não funcionava mais como antes, resultando em problemas de liquidez dos seus clientes. Ao mesmo tempo que alguns clientes sentem dificuldades, a T-SYSTEMS relata haver uma nova demanda, dado que os clientes vêm investindo fortemente, os canais digitais. Outros exemplos são O Boticário e Natura. Durante a Pandemia de COVID-19, com dificuldades tanto com a venda em shopping centers como na venda física, de casa em casa, passaram a direcionar suas vendas via comércio eletrônico.

Vemos vários processos, costumes e formas de consumir da sociedade, não só no Brasil, mas também em outros lugares do mundo, desde a Ásia, o Japão, a Europa, até a África e o continente americano, estão transformando seus padrões. Muito disso está relacionado com o processo de digitalização da economia. Um exemplo é o teletrabalho se tornando corriqueiro. A T-SYSTEMS introduziu o trabalho em casa há três anos e, aos poucos, fomos criando políticas para lidar com esse novo cenário. Para operações que envolvem a administração, usam ferramentas de vídeo conferências. No entanto, na engenharia, onde os funcionários de empresas de vários lugares do mundo trabalham juntos em projetos, por exemplo, na área de construção de navios, na produção de caminhões e carros, essas ferramentas já existiam e já são fortemente usadas. No caso da T-SYSTEMS, estavam mais ou menos preparados e a necessidade nos levou a acelerar o processo.

Outro ingrediente para esse processo de transformação social e econômico é o crime cibernético. Neste ponto, a T-SYSTEMS tem 
soluções de defesa cibernética, mas espera haver uma transformação ainda mais acentuada. Além disso, a empresa relata mudanças também na relação entre empresas e clientes. Por exemplo, as tele-entregas. Os motoboys estão em toda parte da sociedade, servindo de ponte entre empresa e cliente. Outro exemplo, nas comunidades mais carentes, grupos sociais estão interagindo via WhatsApp, criando plataformas de financiamento comunitário e de crowdfunding. Esses processos estão se acelerando com implicações profundas e rápidas sobre a sociedade.

Há três anos, a T-SYSTEMS desenvolve um projeto social numa escola em Blumenau, em um bairro que tem bastante problemas. O objetivo inicial era atender e se preocupar com essas pessoas e com os alunos de uma escola pública e, consequentemente, com as implicações que a automação da indústria e dos serviços pode trazer, decorrentes da digitalização das tarefas, para essas pessoas. A T-SYSTEMS se posiciona como corresponsável sobre essas mudanças e propôs prepará-las para o que vai acontecer daqui a $10 \mathrm{ou}$ 15 anos. Porém, com a Pandemia de COVID-19, esse futuro ficou ainda mais próximo. Com esse desenvolvimento rápido, tem-se que pensar já, mesmo que seja essa uma incumbência dos governos.

Alguns serviços públicos, tanto das prefeituras, como dos governos estaduais estão migrando rapidamente para meios digitais. Por exemplo, aulas remotas já estão sendo realizadas e isso é um desafio imediato para essas comunidades. Atenuando os efeitos sociais imediatos a empresa entende estar optando pela paz social. Segundo relato do gestor da T-SYSTEMS, não se pode olhar apenas para o lado econômico; uma economia e uma cidade só funcionam se houver segurança social e que haja consumidores. Não existe economia sem consumidores.

\section{Possíveis contribuições da pesquisa acadêmica para o tema.}

De modo geral, o tema da Pandemia de COVID19 e multinacionais remete aos efeitos sobre os processos e estratégias de internacionalização de empresas. A observação do cenário de pandemia mostra que há uma tendência de fortalecimento do Estado nas economias tanto desenvolvidas, quanto emergentes. Isso significa a implementação de políticas industriais orientadas para proteger as empresas domésticas e suas respectivas indústrias. Isso implica uma série de ações e medidas que tendem a tornar as medidas de protecionismo mais frequentes, e, cada vez mais, forçam um cenário de arbitrariedade das políticas comerciais internacionais.

Tal fenômeno se torna mais crítico quando o próprio sistema multilateral, liderado pela Organização Mundial do Comércio sofre reveses sucessivos na aplicação de seus princípios básicos de coordenação da cooperação internacional, tal como o abandono do princípio da nação mais favorecida e de não discriminação dos parceiros comerciais.

Por outro lado, muitas das empresas de economias emergentes construíram as suas vantagens de propriedade com a ampliação e diversificação de mercados externos onde atuam, facilitando a construção, especialmente, de vantagens específicas da firma transacionais. Esses efeitos permitiram uma certa sustentabilidade das empresas emergentes na competição global e o surgimento de verdadeiros players globais, inclusive na lista das 200 maiores empresas multinacionais(FORBES, 2017). Aparentemente, o maior risco relativo às mudanças em curso é que muitas empresas poderão perder a fonte de construção de tais vantagens, e, portanto, a sua competitividade internacional.

Para finalizar, as tendências e cenários para as empresas multinacionais podem ser sintetizados nos seguintes pontos. O primeiro ponto, em nível da firma, cada vez mais, as estratégias de enraizamento(da Cruz et al., 2020; Milanez et al., 2019) das empresas no seu contexto local, se tornam extremamente relevantes para as empresas consolidarem sua legitimidade em atuar nos seus entornos. Esse enraizamento nos seus contextos significa, necessariamente, transformar as multinacionais em agentes verdadeiros de redução de desigualdade social. Esse é um ponto, que tende a se tornar chave em termos de trazer novos olhares, novas perspectivas, para empresas multinacionais. 
O segundo ponto, que cada vez as inovações devem migrar para inovações mais abertas, e menos restritas a capacidades internas próprias, até porque a Pandemia de COVID-19 significa também o fechamento de fronteiras e, portanto, pouca mobilidade das competências ao redor do mundo. Então, a empresa tem que substituir esse processo de mobilidade dos recursos humanos por processos mais aprofundados de cooperação e interação com outros agentes e a inovação aberta tende a se tornar mais dinâmica.

O terceiro ponto, as empresas multinacionais procuram repensar seus próprios modelos de gestão organizacional. A Pandemia de COVID-19, potencialmente, pode deixar legados em relação a formas de cooperação entre empresas, subsidiárias, parceiros e investidores. Isso precisa ser pensado em termos de novos modelos de negócios. Como último ponto, salienta-se a importância dos fatores políticos. Os aspectos políticos e geopolíticos na distribuição de capital, nos investimentos, de modo geral, se tornaram fatores relevantes, o que abre espaço, do ponto de vista de pesquisa, para estratégias de nãomercado, que são realmente verdadeiras oportunidades para aprofundar o entendimento das estratégias de empresas multinacionais em contextos turbulentos e disruptivos.

\section{CONCLUSÃO}

Inicialmente, este ensaio se propunha a provocar reflexões sobre os efeitos da pandemia de COVID-19 sobre as empresas multinacionais e seus reflexos na economia. Inicialmente, apresentou-se os elementos para a discussão, que abrangeram os efeitos da pandemia sobre a globalização, levando em conta implicações de ordem contextual como as implicações macroeconômicos da Pandemia, efeitos e implicações para a globalização e os efeitos no investimento direto em países emergentes.

Após a descrição do cenário possível de ser interpretado em maio de 2020, no auge da Pandemia de COVID-19, sob o olhar da gestão, buscou-se reflexões sobre os efeitos imediatos da Pandemia nas Empresas Multinacionais, tomando por base a empresa T-SYSTEMS, subsidiária brasileira da gigante alemã da área de telecomunicação e tecnologia da informação, a TELEKOM. Finalmente, no intuito de materializar as reflexões e provocar os pesquisadores da área de negócios internacionais, foram desenhadas possíveis contribuições da pesquisa acadêmica para o tema.

Ao final deste ensaio, discutido, redigido e publicado durante a pandemia, os autores têm ciência da limitação da racionalidade humana, sabiamente defendida por Herbert Simon (1957). Tanto as consequências nocivas da Pandemia COVID-19 serão sentidas e reveladas ainda no decorrer da década pelos seus efeitos nefastos sobre a população menos assistida, como também estará aberto um vasto espaço para pesquisa, no intuito de minimizar tais efeitos e identificar padrões de comportamento que possam ser agregados à tomada de decisão via oportunidades de negócios e detecção de novos padrões de comportamento.

Conclui-se, também, que o papel do Estado está sub judice, tanto para dar suporte para a economia como para gerar emprego, inovação e reduzir desigualdades. Tais temas já estão na pauta das multinacionais, que passaram a ter papel determinante nas duas últimas décadas no quesito de responsabilidade socioambiental e que serão essenciais na retomada econômica esperada para a década de 2020 .

\section{REFERÊNCIAS}

Abramovitz, M. (1986). Catching up, forging ahead, and falling behind. Journal of Economic History, 385-406.

Amal, M. (2016). Foreign direct investment in Brazil: Post-crisis economic development in emerging markets. In FDI and Economic Growth Foreign Direct Investment in Brazil (pp. 185-202). Academic Press.

Batschauer da Cruz, C. B., Eliete Floriani, D., \& Amal, M. (2020). The OLI Paradigm as a comprehensive model of FDI determinants: a subnational approach. International Journal of Emerging Markets, ahead-of-print. https://doi.org/10.1108/IJOEM-07-2019-0517 
Enderwick, P., \& Buckley, P. (2020). Rising regionalization: will the post-COVID-19 world see a retreat from globalization? Transnational Corporation Journal, 27(2), 99-112. https://papers.ssrn.com/sol3/papers.cfm?abstract _id=3692317

FMI. (2020). WORLD ECONOMIC OUTLOOK REPORTS.

https://www.imf.org/en/Publications/WEO/Issues /2020/06/24/WEOUpdateJune2020

FORBES. (2017). Top Multinational Performers. The List of 200 Top Multinational Performers. https://www.forbes.com/top-multinationalperformers/list/\#tab:rank

Gereffi, G. (2020). What does the COVID-19 pandemic teach us about global value chains? The case of medical supplies. Journal of International Business Policy, 3(3), 287-301. https://doi.org/10.1057/s42214-020-00062-w

Irwin, D. W. (2020). The pandemic adds momentum to the deglobalization trend. Peterson Institute for International Economics. https://www.piie.com/blogs/realtime-economicissues-watch/pandemic-adds-momentumdeglobalization-trend

Liy, M. V. (2019). Terras raras, o ouro do século $X X I$, são a arma da China na guerra tecnológica. EI País Brasil. https://brasil.elpais.com/brasil/2019/06/06/econo mia/1559832258_232021.html

McKinsey \& Company. (2020). The Next Normal: The recovery will be digital. In The Next Normal (Issue August).

Milanez, B., Dos Santos, R. S. P., Mansur, M. S., \& Coelho, T. P. (2019). Buscando Conexões para o Desastre: Poder e Estratégia na Rede Global de Produção da Vale. Internext, 14(3), 265. https://doi.org/10.18568/internext.v14i3.561

Mu, Q., \& Lee, K. (2005). Knowledge diffusion, market segmentation and technological catch-up: The case of the telecommunication industry in
China. Research Policy, 34(6), 759-783. https://doi.org/10.1016/j.respol.2005.02.007

Parente, R., Melo, M., Andrews, D., Kumaraswamy, A., \& Vasconcelos, F. (2020). Public sector organizations and agricultural catch-up dilemma in emerging markets: The orchestrating role of Embrapa in Brazil. Journal of International Business Studies. https://doi.org/10.1057/s41267020-00325-x

Petricevic, O., \& Teece, D. J. (2019). The structural reshaping of globalization: Implications for strategic sectors, profiting from innovation, and the multinational enterprise. Journal of International Business Studies, 50(9), 1487-1512. https://doi.org/10.1057/s41267-019-00269-x

Ramamurti, R. ., \& Singh, J. V. (2009). Emerging Multinationals in Emerging Markets. Cambridge University Press.

Rapoza, K. (2020). Why Is The U.S. So Ridiculously Dependent On China? FORBES. https://www.forbes.com/sites/kenrapoza/2020/0 4/30/why-is-the-us-is-so-ridiculously-dependenton-china/\#71e3370c56b5

Rocha, K. (2020). Investimentos privados em infraestrutura nas economias emergentes: a importância do ambiente regulatório na atração de investimentos.

https://www.ipea.gov.br/portal/images/stories/P DFs/TDs/td_2584.pdf

Rodeck, D. (2020). Alphabet Soup: Understanding the Shape of a COVID-19 Recession. FORBES.

https://www.forbes.com/advisor/investing/covid19-coronavirus-recession-shape/

Silva, N., \& Fleury, M. L. (2012). Estratégias De Transferência De Conhecimento Em Multinacionais Brasileiras: Estudo Comparativo Entre As Subsidiárias. Internext: Revista Electrônica de ..., October, 1-33. http://search.ebscohost.com/login.aspx?direct=tr ue\&profile $=$ ehost $\&$ scope $=$ site\&authtype $=$ crawler $\& \mathrm{jrnl}=19804865 \& A N=85883259 \& h=b S r H e W V f H+$ 
aBhqWrAOwNAVR+k8ikqkhTs4y90XRrzRPwq5swu rUKmiYgtRTE1GMbRbHssOa023JEr2gQGTsYOg==\& $\mathrm{crl}=\mathrm{c}$

Simon, H. A. (1957). A Behavioral Model of Rational Choice. In Models of Man, Social and Rational: Mathematical Essays on Rational Human Behavior in a Social Setting. Wiley.

Stiglitz, J. E. (2018). Trump and Globalization. Journal of Policy Modeling, 40(3), 515-528. https://doi.org/10.1016/j.jpolmod.2018.03.006

Tomelin, J., Amal, M., Hein, N., \& Carpes Dani, A. (2018). Foreign direct investment in the G-20: to what extent do institutions matter? RAUSP Management Journal, 53(3), 404-421. https://doi.org/10.1108/RAUSP-04-2018-003
UNCTAD. (2020). Impact of the COVID-19 Pandemic on Global FCl and GVCs. https://unctad.org/en/PublicationsLibrary/diaeiain f2020d3_en.pdf

Wadhwa, K., \& Reddy, S. S. (2011). Foreign direct investment into developing Asian countries: the role of market seeking, resource seeking and efficiency seeking factors. International Journal of Business and Management, 6(11), 219.

Werlang, N. B., Dalbosco, I. B., Floriani, D. E., \& Rossetto, C. R. (2014). Dynamic Capabilities and the Inward Internalisation Process of an Argentine Multinational Directed To. Revista Eletrônica de Negócios Internacionais, 9(1), 23-40.

\section{Sobre os autores}

Mohamed Amal - Universidade Regional de Blumenau - FURB, Blumenau, Santa Catarina (Brasil). Email: mohamedamal.amal@gmail.com. Orcid id: https://orcid.org/0000-0001-7851-267X

Markus Blumenschein - T-Systens - Blumenau, Santa Catarina, (Brasil). Email: markus.blumenschein@tsystems.com

Sílvio Luís de Vasconcellos - Escola Superior de Propaganda e Marketing - ESPM, São Paulo, (Brasil). Email: silvio.vasconcellos@espm.br. Orcid id: https://orcid.org/0000-0002-9986-679X

\section{Como citar este artigo:}

Amal, M., Blumenschein, M., \& de Vasconcellos, S. (2021). Reflexões sobre Empresas Multinacionais e a Pandemia de Covid-19. Internext, 16(1), 01-11. doi:http://dx.doi.org/10.18568/internext.v16i1.636 